\title{
Swelling and Mechanical Behaviour of Natural Rubber Vulcanisate Filled with Leather Wastes (Buffing Dust) and Its Modeling
}

\author{
Michael Ifeanyichukwu Ugbaja ${ }^{1}$, Francis Ngozichi Onuoha ${ }^{2,}$, Uche Ibeneme ${ }^{1}$, \\ Maryann Ifeoma Uzochukwu ${ }^{1}$, Henry Opara ${ }^{1}$, Isaac Ndubuisi Mbada ${ }^{3}$ \\ ${ }^{1}$ Department of Polymer Technology, Nigerian Institute of Leather and Science Technology (NILEST), Zaria, Nigeria \\ ${ }^{2}$ Department of Polymer and Textile Engineering, Federal University of Technology Owerri, Imo State, Nigeria \\ ${ }^{3}$ Department of Transport Centre, Nigerian Institute of Transport Technology, Zaria, Nigeria \\ Email address: \\ ugboajamichael@yahoo.com (M. I. Ugbaja), francorev2007@yahoo.com (F. N. Onuoha) \\ ${ }^{*}$ Corresponding authors
}

\section{To cite this article:}

Michael Ifeanyichukwu Ugbaja, Francis Ngozichi Onuoha, Uche Ibeneme, Maryann Ifeoma Uzochukwu, Henry Opara, Isaac Ndubuisi Mbada. Swelling and Mechanical Behaviour of Natural Rubber Vulcanisate Filled with Leather Wastes (Buffing Dust) and Its Modeling. American Journal of Applied Scientific Research. Vol. 2, No. 2, 2016, pp. 6-11. doi: 10.11648/j.ajasr.20160202.11

Received: April 1, 2016; Accepted: May 17, 2016; Published: August 4, 2016

\begin{abstract}
The swelling and mechanical behavior of untreated leather waste particles (buffing dust, BD) in natural rubber have been studied. Mechanical and swelling properties of the natural rubber (NR) composites containing the buffing dust have been discussed. The properties of the composites were found to increase with the increase in filler loading. Polymer composites based on leather wastes as fillers are reported to be useful for many applications such as in construction materials, automobile interior moldings, heat and sound insulating boards, shoe soles, flooring materials and moldings with good anti-static properties, air permeability, and good appearances.
\end{abstract}

Keywords: Leather Waste (Buffing Dust), Natural Rubber, Swelling, Mechanical, Polymer Composites, Modeling, Vulcanizate

\section{Introduction}

In natural rubber compounding, fillers are major additives. Incorporation of fillers into natural rubber matrix enhances properties such as tensile strength, modulus, tear strength, abrasion resistance, stiffness and processibility. Also significantly reduced by the addition of additives is the cost of the manufactured rubber products $[1,2]$. The mechanism of elastomeric reinforcement by fillers has been reviewed by several workers [3]. One of the mechanisms by which particulate fillers reinforces elastomers is that reported by Beueche and Fleminert [4]. They considered that the effect of filler is to increase the number of chains, which shared the load of a broken polymer chain. Fillers used in rubber industries may be classified on the basis of sources, properties and colour. Those grouped on the basis of sources could be organic or inorganic fillers. Inorganic fillers are calcium carbonate, barites, silica etc. while that of the organic fillers are phenolic resins, cyclised natural rubber etc. they are categorized either as reinforcing or non-reinforcing. While reinforcing filler on inclusion into a rubber mix increase the tensile strength, tear strength and abrasion resistance, the non-reinforcing only help to reduce the cost of product and act as diluents. Examples of reinforcing fillers are carbon black, silica etc. while examples of nonreinforcing fillers are mica powder, barium sulphate etc. [5].

In the rubber industry, fillers that are commonly in use are carbon black, calcium carbonate and china clay. Calcium carbonate $\left(\mathrm{CaCO}_{3}\right)$ had attracted considerable interest in recent years due to its availability and low cost [3].

For filled vulcanizates, the efficiency of reinforcement depends on a complex interaction of several filler related parameters. These include particle size, particle shape, particle dispersion, surface areas, surface reactivity, structure 
of the filler and the bonding quality between the fillers and the rubber matrix [6]. Again, reinforcing fillers should possess a small particle size that is $<1000 \mathrm{~nm}$, a chemical active surface and a surface which is both porous and very irregular in shape to maximize surface contact between rubber and filler $[7,8]$.

The leather is a natural polymer consisting of collagen fibrescrosslinked in a three dimensional structure. Chrome leather tanning results in improved appearance, physical properties and chemical and biological resistance to leather but the process leads to the emission of solid and liquid wastes into the environment. The entire leather operations such as trimming, shaving and cutting result with more than $50 \%$ of the raw hide being rejected as waste. Processing of one ton wet salted hide yields only $200 \mathrm{kgs}$ of leather but over $600 \mathrm{Kgs}$ is rejected as solid waste. Of the total waste, more than $50 \%$ is considered as potentially hazardous because of the presence of the chromium. An important consideration is the possibility of the oxidation of trivalent chromium to hexavalent chromium, which is considered to be even more hazardous. When waste leather fibres are added to elastomers, it could function as short fibre reinforcement for the matrix provided the inherent fibrous nature of the former is retained during processing. Since processing of elastomers is carried out relatively at high temperatures, retention of the fibrous nature in the leather under such conditions, however, is very difficult. It is, therefore, prudent to use and consider the leather waste in the particulate form and study its effectiveness either as filler or as a processing aid in elastomeric formulations. Use of leather in rubber formulations is then bound to affect the vulcanization characteristics and vulcanisate properties of the rubber significantly as it is a biomaterial with many reactive functional groups present in it, apart from large quantities of trivalent chromium. Natural rubber- scrap rubber vulcanisates containing untreated leather particles reduces the vulcanization characteristics and mechanical properties of the compound, but improves the incorporation and higher amount of loading of scrap rubber [9]. In this article, the effect of untreated leather particles on the mechanical and swelling properties of natural rubber composites has been investigated.

\section{Experimental}

\subsection{Material}

Natural rubber (NSR 10) was collected from the Polymer recycling workshop of the Department of Polymer Technology, NILEST, Zaria. The leather waste (buffing dust) used in this study, were obtained from the tannery section of the Nigerian Institute of Leather and Science Technology (NILEST), Zaria. The leather waste was dried at $100^{\circ} \mathrm{C}$ for 15 minutes in an air oven and finally was shredded into fine particles. Other materials such as zinc oxide $(\mathrm{ZnO})$, stearic acid, sulphur, processing oil, and MBTS were used as supplied.
Waste chrome leather shavings obtained from a local tannery usually contains $2.5 \%$ chromium and $11.21 \%$ nitrogen.

\subsection{Compounding}

Compounding was done on a two roll mill (Reliable, model no. 5183, USA), as per the base formulation is given in Table 1. Natural rubber was masticated and after a smooth band was formed on the mill. Then zinc oxide $(\mathrm{ZnO})$ and stearic acid were introduced into the smooth rubber band, followed by the addition of the filler particles and the processing oil. After complete mixing and band formation were ensured, accelerators and sulphur were added. Appropriate nip gaps were maintained and 3/4 cut were made during the mixing process in order to get the uniform mix.

Table 1. Typical formulation for leather waste (buffing dust)- filled natural rubber (NR).

\begin{tabular}{lll}
\hline Materials & Pbw $(\mathbf{g})$ & \%phr \\
\hline NR & 40 & 100 \\
Filler & $0-16$ & $0-40$ \\
Stearic acid & 0.4 & 1.0 \\
Zinc oxide & 2.0 & 5.0 \\
MBTS & 0.6 & 1.5 \\
TMQ & 0.6 & 1.5 \\
Processing oil & 0.6 & 1.5 \\
Sulphur & 0.6 & 1.5 \\
\hline
\end{tabular}

\subsection{Swelling and Mechanical Properties Measurement}

Tensile sheets for the evaluation of mechanical properties were compression moulded using a 10 tons hydraulic press (Carver Model $3851-0$ ) at $150^{\circ} \mathrm{C}$ for 15 minutes. Mechanical properties of the moulded specimens were measured according to ASTM D 412 and ASTM D 624 standards [10], using a tensometer ( Zwick/Roell Type: BDO-FBO- $5^{\text {th }}$ Serial no: 653644$)$ at a cross head speed of $500 \mathrm{~mm} / \mathrm{min}$. The shore A hardness of the vulcanisate was measured in a Durometer according to ASTM D 2240. Swelling ratio, expressed as \% weight, was determined in water after immersing the vulcanisates in the medium for about $24 \mathrm{hrs}$.

\section{Results and Discussion}

The effects of leather particles (buffing dust) on the mechanical properties of the natural rubber vulcanisates are shown in Table 2. Vulcanisates containing leather particles have exhibited significant improvements in mechanical properties when compared to the natural rubber vulcanisate that does not contain any filler. The tensile strength (T. S) increases with increase in filler content of the filled NR vulcanisates. The result on modulus showed that the modulus of the NR vulcanizates increases as the filler content in the filled NR vulcanisates was increased. For the $\%$ elongation at break (E. b), the results showed a decrease in \% elongation at 
break as more filler are being added to the NR vulcanisates. The hardness increases steadily with the increasing quantity of filler in the rubbervulcanisates.

Table 2. Mechanical properties of NR vulcanisates filled with leather waste (buffing dust).

\begin{tabular}{lllll}
\hline $\begin{array}{l}\text { Filler content } \\
(\%)\end{array}$ & $\begin{array}{l}\text { T.S } \\
(\mathbf{M P a})\end{array}$ & E.b (\%) & $\begin{array}{l}\text { Modulus } \\
(\mathbf{M P a})\end{array}$ & $\begin{array}{l}\text { Hardness } \\
(\mathbf{1 5 s e c})\end{array}$ \\
\hline 0 & 6.80 & 21.00 & 32.27 & 24.70 \\
10 & 10.80 & 10.70 & 110.44 & 27.00 \\
20 & 11.80 & 8.20 & 129.58 & 29.00 \\
30 & 12.20 & 6.95 & 175.34 & 37.70 \\
40 & 13.80 & 5.80 & 237.28 & 49.00 \\
\hline
\end{tabular}

\subsection{Tensile Strength}

Examining Figure 1, with regard to tensile strength shows great improvement in reinforcement of filled NR vulcanisates The tensile strength was observed to increase with increasing filler content. Several workers [11, 12] that significant reinforcement is only attainable when the particle size of the filler is of the order of 0.02-0.05 $\mu \mathrm{m}$. Parkinson [6], found that decreasing the particle size of carbon black filler generally enhanced mechanical properties such as tensile and tear strength. The tensile strength at $30 \mathrm{wt} \%$ is double the strength of unfilled natural rubber.

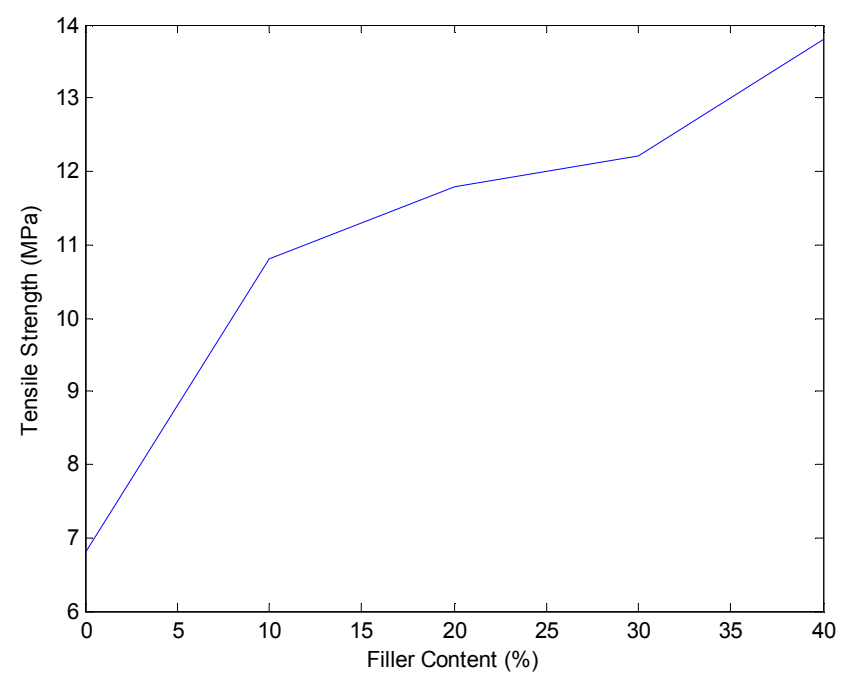

Fig 1. Tensile strength as a function of filler content for leather waste (buffing dust).

\section{2. \% Elongation at Break (E. b)}

Figure 2 shows that the elongation at break of the filled NR vulcanisates decreases with increasing filler content. Decreased elongation at break with increasing filler content may be due to the stiffening of the polymer chain and hence resistance to stretch when strain is applied $[13,14]$.

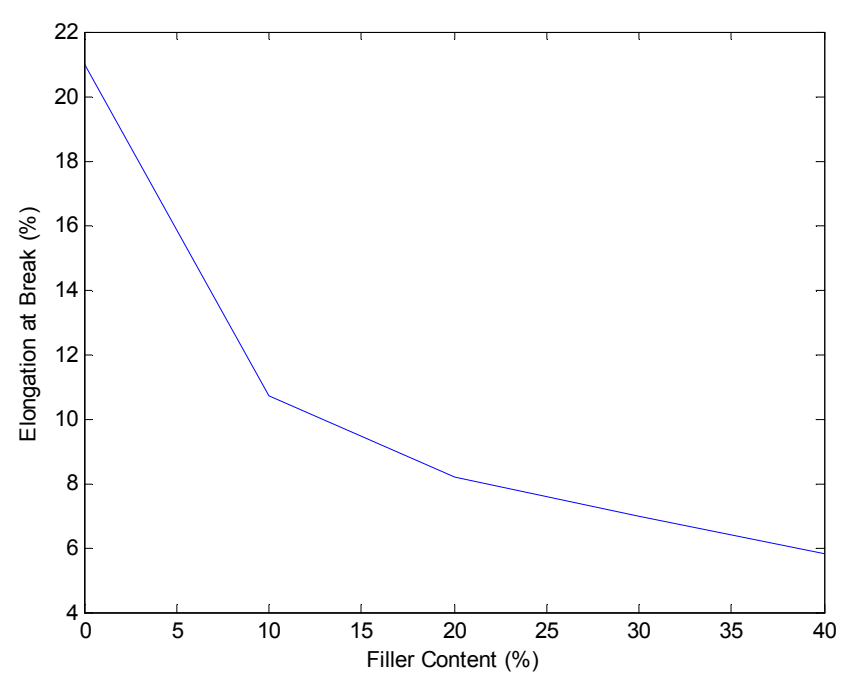

Fig. 2. \% elongation at break as a function of filler content for leather waste (buffing dust).

\subsection{Modulus}

As for the modulus properties, figure 3 shows that the modulus of the NR vulcanisate increases as the filler content in the vulcanisate was increased. Parkinson (6) and Wagner (15) reported that stiffness or modulus for filled vulcanized NR can be enhanced by improving the surface area and surface reactivity of fillers.

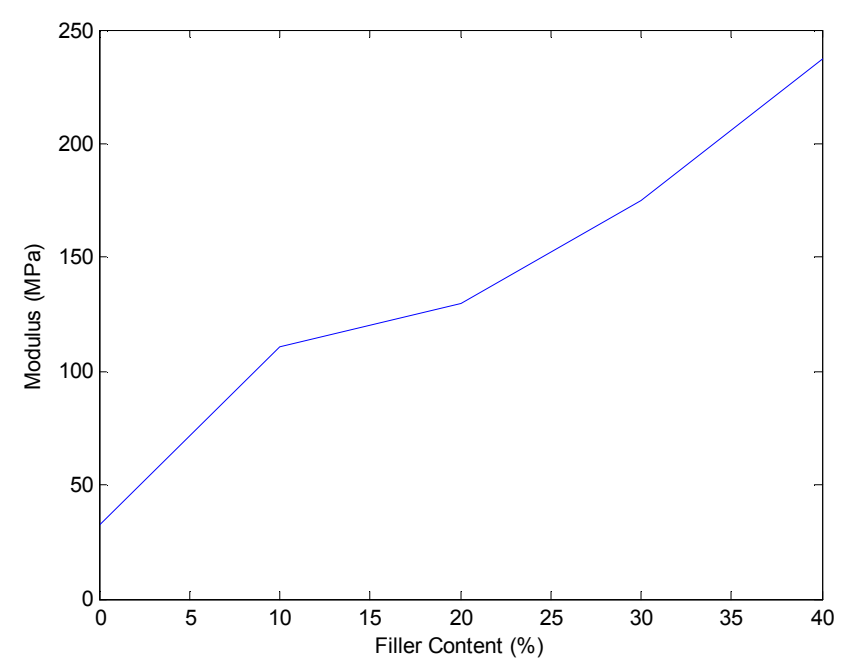

Fig. 3. Modulus at $100 \%$ as a function of filler content for leather waste (buffing dust).

\subsection{Hardness}

Figure 4 shows that the hardness increases with increasing filler content. The hardness enhancement can be attributed to better wetting and dispersion of the fillers which happen to be a biomaterial. 


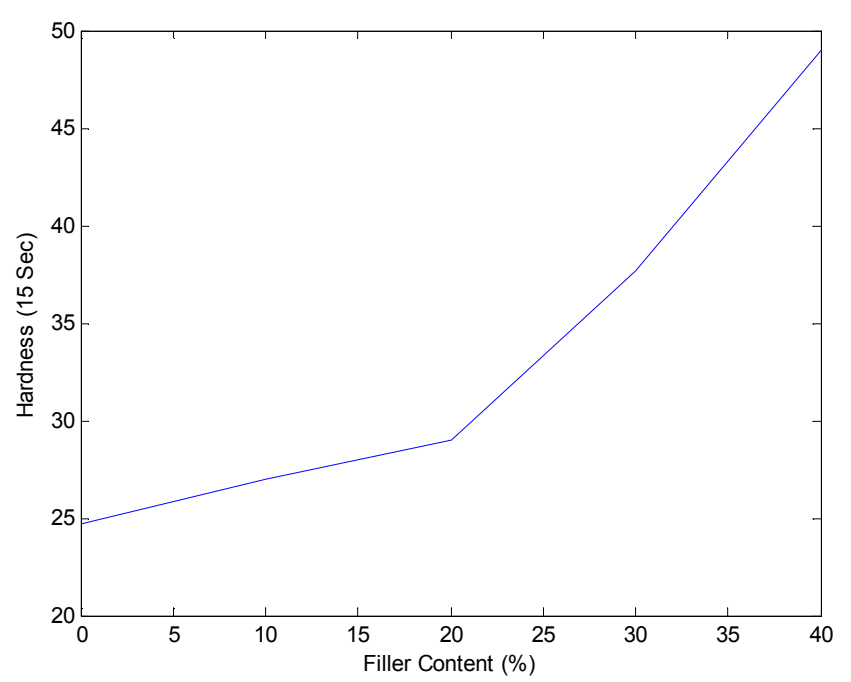

Fig. 4. Hardness as a function of filler content for leather waste (buffing dust).

\subsection{Swelling Analysis}

Water plays an important role on the properties of leather as with other proteins. Earlier studies on water vapour absorption [16] indicate that within the range of water uptake which is possible from the vapour phase, the affinity of water uptake for collagen is not diminished by chrome tanning. Both hide and leather become brittle and unpleasant to touch if the water present in the system is completely removed. During vulcanization at high temperatures, some of the water molecules present in the leather fibres would be completely removed. Since leather is known for its excessive swelling in aqueous media, it would be of great interest to study the swelling behavior of natural rubber vulcanisates containing leather. The swelling behavior of natural rubber vulcanisates containing untreated leather waste (buffing dust) in water is shown in Figure 5.

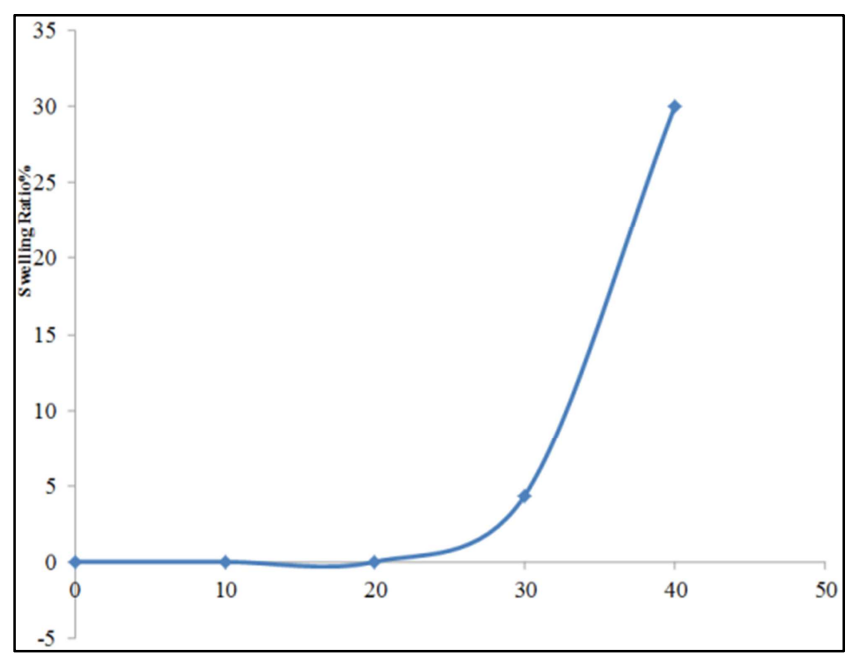

Filler Content (\%)

Fig. 5. Swelling behavior in water as a function of filler content for leather waste (buffing dust).

\subsection{Modeled Results}

\subsubsection{Tensile Strength}

Model equation for the tensile strength is:

$$
f(x)=0.00035 x^{3}-0.02486 x^{2}+0.6093 x+6.809
$$

Goodness of fit:

SSE: 0.005143

R-square: 0.9998

Adjusted R-square: 0.9993

RMSE: 0.07171

The modeled graph is shown in Figure 6a while the analysis curve is represented in Figure 6b. There was a slight deviation observed in the modeled data. Between 20 to 30 wt $\%$, the model curve showed an upward deviation. The optimum tensile strength is observed at $24 \mathrm{wt} \%$ of the filler content.

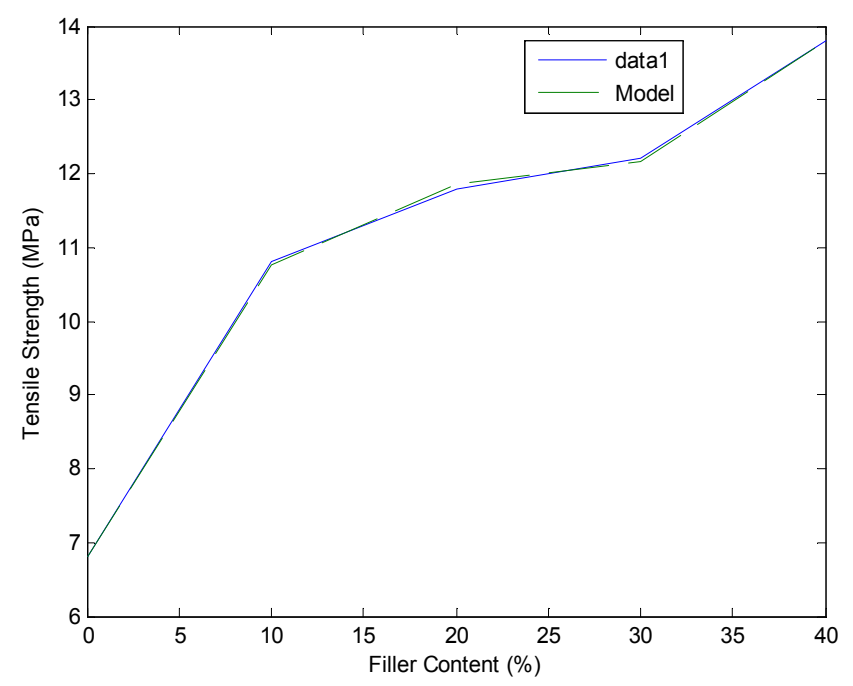

Fig. 6a. Modeled graph for tensile strength as a function of filler content.

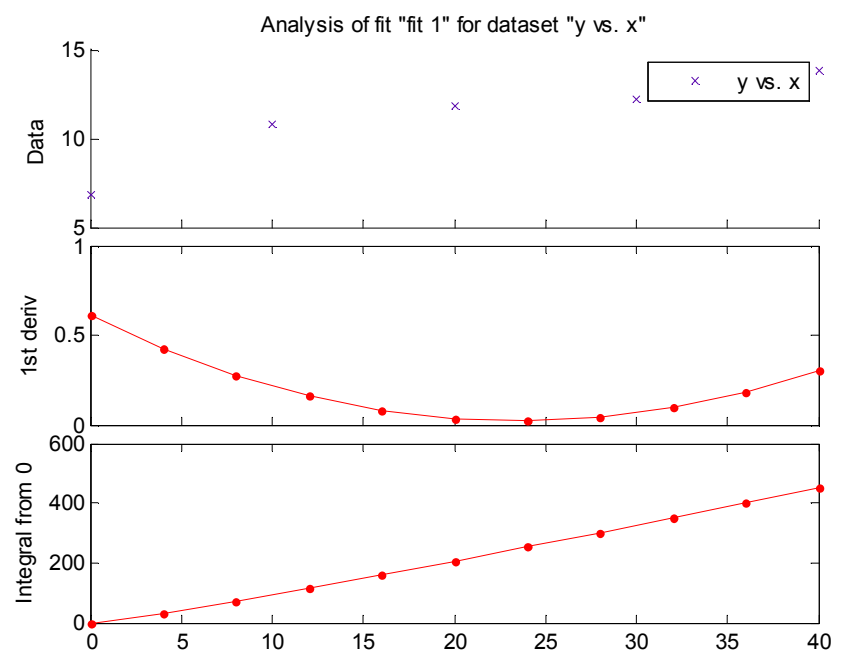

Fig. 6b. Analysis Curve for Tensile Strength. 


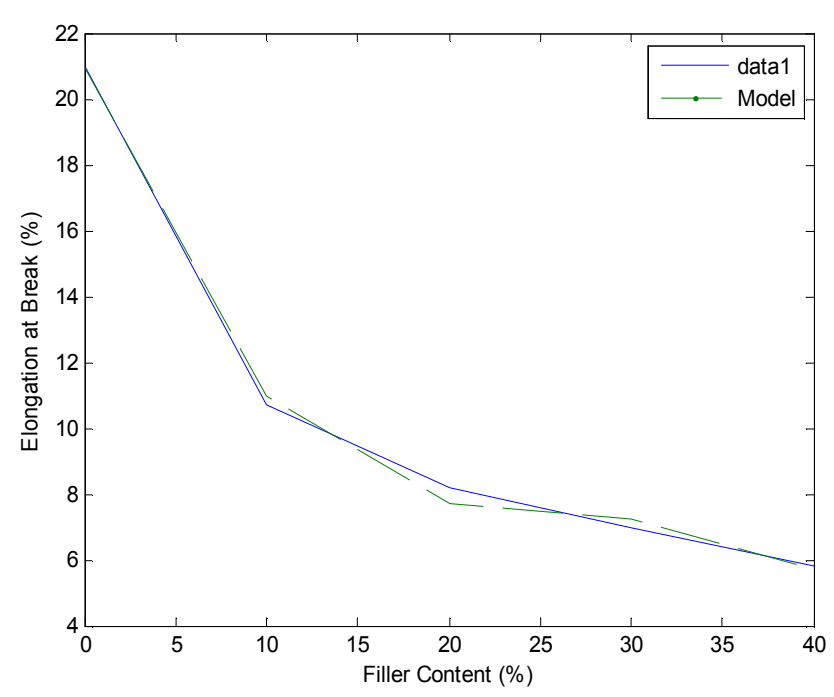

Fig. 7a. Modeled graph for elongation at break as a function of filler content.

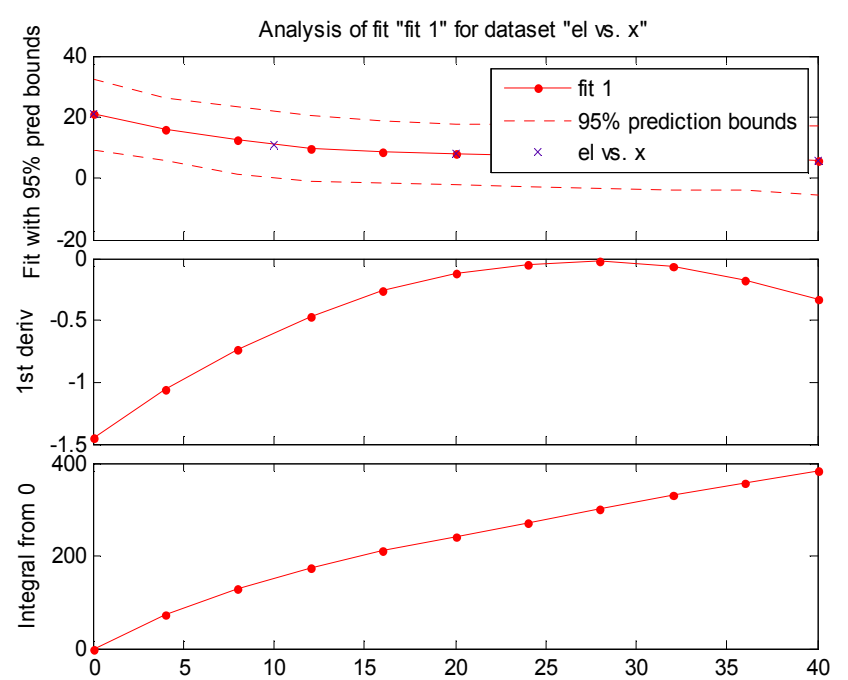

Fig. 7b. Analysis Curve for elongation at break as a function of filler content.

\subsubsection{Elongation at Break}

Linear model Poly3:

$$
f(x)=-0.0006417 x^{3}+0.05246 x^{2}-1.452 x+20.92
$$

Coefficients (with $95 \%$ confidence bounds):

Goodness of fit:

SSE: 0.4166

R-square: 0.9972

Adjusted R-square: 0.9889

RMSE: 0.6454

The modeled graph is represented in Figure $7 \mathrm{a}$ and the analysis curve in Figure $7 \mathrm{~b}$. There was an upward deviation between 5 to $7.5 \mathrm{wt} \%$, a downward deviation between 15 to $25 \mathrm{wt} \%$ and then an upward deviation between 30 to $35 \mathrm{wt} \%$. Optimum elongation at break was obtained at $27.5 \mathrm{wt} \%$.

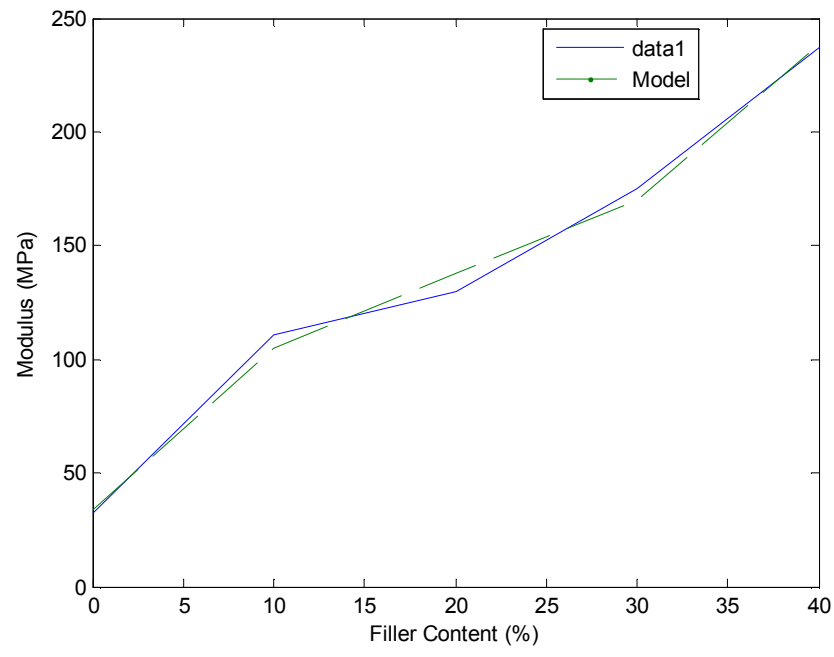

Fig. 8a. Modeled graph for modulus as a function of filler content.

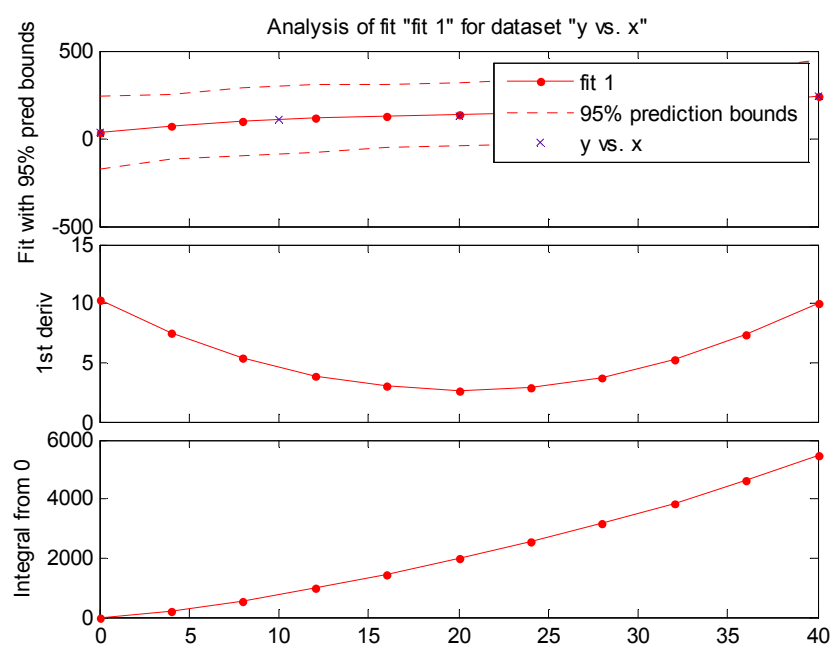

Fig. 8b. Analysis curve for modulus as a function of filler content.

\subsubsection{Modulus}

Linear model Poly3:

$$
f(x)=0.006267 X^{3}-0.3802 x^{2}+10.31 x+33.64
$$

Coefficients (with 95\% confidence bounds):

Goodness of fit:

SSE: 131.9

R-square: 0.9943

Adjusted R-square: 0.9773

RMSE: 11.48

The modeled graph of modulus versus filler content is shown in Figure 8a and the analysis curve in Figure 8b. Optimum modulus was obtained at $20 \mathrm{wt} \%$.

\subsubsection{Hardness}

Linear model Poly3:

$$
f(x)=0.0002417 x^{3}+0.003143 x^{2}+0.09512 x+24.86
$$

Goodness of fit:

SSE: 1.76

R-square: 0.9956 
Adjusted R-square: 0.9823

RMSE: 1.327

The model curve of hardness vs. filler content is shown in Figure 9(a) while the analysis curve is in Figure 9(b).

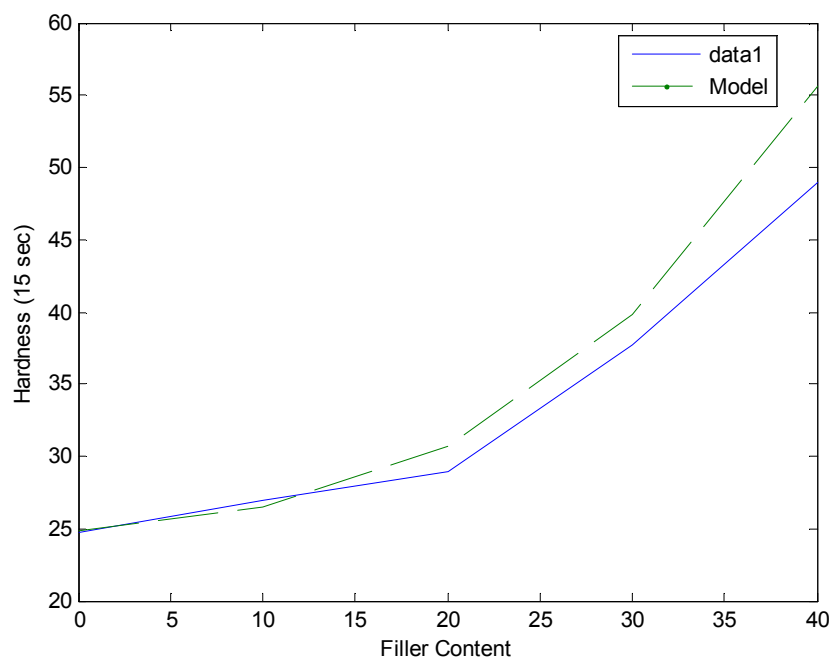

Fig. 9a. Modeled graph for hardness as a function of filler content.

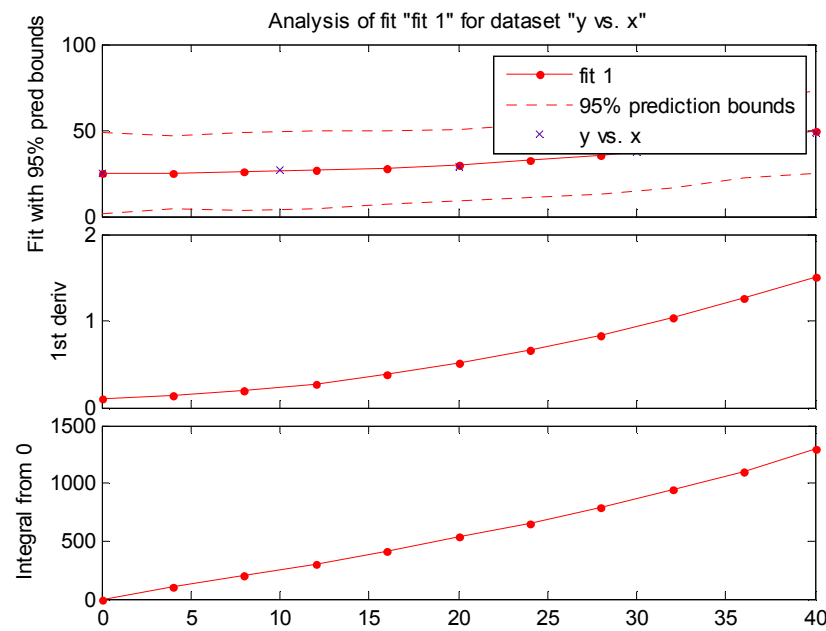

Fig. 9b. Analysis Curve for hardness as a function of filler content.

\section{Conclusion}

Buffing dust can be incorporated into formulations of natural rubber vulcanisate as reinforcing filler. The resulting composites showed an improvement in hardness and tensile properties. The presence of leather waste in natural rubber vulcanisate can lead to increase in swelling when immersed in water.

\section{References}

[1] Mark H. F. (2001) Encyclopedia of Polymer Science and Technology, Interscience, New York Vol. 12: 42

[2] Okieimen, F. E. and Imanah, J. E. (2003); The Characterisation of Agricultural Waste Products as Fillers in NR Formulation, Nig. J. Polym.Sci. and Tech, Vol. 3, 1: 210-216.

[3] Danneberg, E. M. (1981), Proceeding of International Rubber Conference, Loughborough.

[4] Fleminert, G and Bueche, C. (1957); "Light Reinforcement Filler" A Paper presented before the Swedish institute of Rubber Technology.

[5] Blow, C. and Hepburn, C. (1971); Rubber Technol and Manufacture, Butter Worth Publishers London, $3^{\text {rd }}$ Ed. 188.

[6] Parkinson, D. (1957); Reinforcement of Rubber, Lakeman and Co. London, 12.

[7] Hepburn, C. (1984); Filler reinforcement of Rubber Plastic and Rubber international No. 9:11-15.

[8] Morton, M. (1987); Rubber Technology, $3^{\text {rd }}$ Edn. Van Nostrand, New York; 74.

[9] Ravichandran, K. \& Natchimuthu, N. (2005). Polimeros., Anna University, India, 15, 2.

[10] ASTM 1510 (1983); American Society for Testing and Materials.

[11] Nasir, M. and Choo, C.H. (1987) Euro. Polym J. 25,355.

[12] Mehta, P.K. and Pitt, N. (1974) Rice by-Products conference Valencia, 76.

[13] Rivin, D. (1963); RubbChem \& Tech 36, 729.

[14] Hepburn, C and Blow, C. M. (1971); Rubber Technology and Manufacture $3^{\text {rd }}$ Edition, Butter Worth Publishing 188.

[15] Wagner, M. P. (1976); Rubb. Chem. Tech. 49,704.

[16] Kremen, S. S. and Lollar, R. M. (1951). J. Am. Leather Chem., Ass. 46: 34. 